
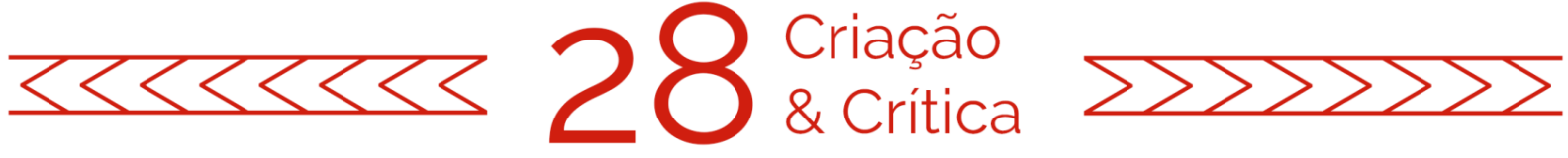

\title{
DO QUE ESTAMOS FALANDO QUANDO FALAMOS DE ESCRITA CRIATIVA
}

\author{
Luís Roberto Amabile ${ }^{1}$
}

Resumo: O presente ensaio discute a Escrita Criativa como um espaço de encontro. A discussão se alicerça por meio de uma cartografia de definições de Escrita Criativa, mesclada às reflexões advindas da experiência do autor como ministrante de oficinas e pesquisador da área. A metodologia consiste em investigar fontes diversas, como sites de universidades, trabalhos acadêmicos, livros teóricos, manuais, centrais de acolhimentos de escritores e, por fim, relatar experiências pessoais como ministrante de oficinas e cursos de Escrita Criativa para propor uma definição própria. A base teórica inclui Karen Lockney, D. G. Myers, Paul Dawson, Mark Mcgurl, João de Mancelos e Luiz Antonio de Assis Brasil.

PALAVRAS-CHAVE: Escrita Criativa, comunidade literária, processo de criação, leitura, ambiente estimulante, teoria da literatura.

\section{WHAT ARE WE TALKING ABOUT WHEN WE TALK ABOUT CREATIVE WRITING}

ABSTRACT: This essay discusses Creative Writing as a meeting place. The discussion is based on a cartography of definitions of Creative Writing, mixed with reflections from the author's experience as a workshop teacher and researcher in the field. The methodology consists of investigating different sources, such as university websites, academic works, theoretical books, manuals, reception centers for writers and, finally, reporting personal experiences as a teacher of Creative Writing workshops and courses in order to propose a specific definition of Creative Writing. The theoretical basis includes Karen Lockney, D. G. Myers, Paul Dawson, Mark Mcgurl, João de Mancelos and Luiz Antonio de Assis Brasil.

KEYWORDS: Creative Writing; literary community; creation process; reading; stimulating environment, theory of literature.

\section{Um ponto de convergência}

Numa entrevista de 2016 e bastante lembrada à ocasião de sua morte, em 2020, Luis Supúlveda afirma que sempre considerou a literatura como um ponto de encontro: "Primeiro, é um ponto de encontro do escritor com a sua própria memória, com as suas referências culturais e sociais. Depois, é um ponto de encontro entre dois estados de alma: o do escritor, quando estava a escrever, e o do leitor, no momento em que lê"2. Há um lugar para o qual convergem as duas ideias de ponto de encontro proferidas por

\footnotetext{
${ }^{1}$ Professor na Escola de Humanidades da PUCRS. Doutor em Teoria da Literatura (2017) e Escrita Criativa (2020) / (luisrobertoamabile@gmail.com).

2 Disponível em: <https://expresso.pt/coronavirus/2020-04-16-Luis-Sepulveda-o-escritor-que-via-a-literaturacomo-ponto-de-encontro-com-o-leitor>. Acesso em 25 out. 2020.
} 

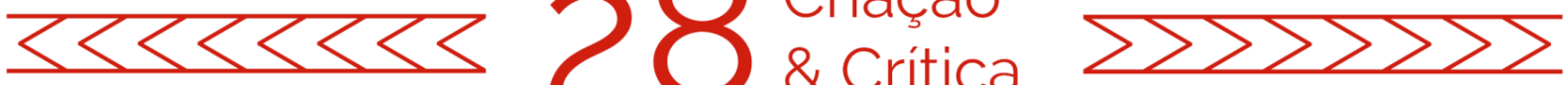

Sepúlveda ${ }^{3}$. Tal lugar é a oficina de criação, um espaço que agrega vários agentes da prática literária, cada qual com um percurso, cada qual com sua voz social e percepção de mundo: o ministrante que, ao menos numa boa oficina, também é um estudioso e orienta os participantes a partir de textos exemplares, os aprendizes de escritores que buscam encontrar seu próprio jeito de escrever, que aprendem a exercer a leitura atenta e que são os primeiros leitores dos colegas.

A oficina de criação literária está na base da Escrita Criativa. De longa tradição nas universidades de países de língua inglesa, o eixo de estudos em Escrita Criativa se espalhou pelo mundo a partir da década de 1970 e, nos últimos anos, vem ganhando espaço em instituições brasileiras ${ }^{4}$. Apesar disso, tal eixo de estudos é pouco discutido no país, assim como o próprio conceito de Escrita Criativa permanece nebuloso.

Tomando como base as considerações listadas até aqui, este ensaio constrói uma concepção da Escrita Criativa, inclusive pensando-a no contexto brasileiro. Tal construção se pauta pela ideia do encontro e se alicerça por meio de uma cartografia de definições de Escrita Criativa, mesclada às reflexões advindas de minha experiência como ministrante de oficinas e pesquisador da área. Desse modo, fontes diversas foram vasculhadas, como sites de universidades, trabalhos acadêmicos, livros teóricos, manuais, centrais de acolhimentos de escritores. Por fim, é proposta uma definição de Escrita Criativa.

\section{Para não afundar num "pântano de subjetividade"}

A definição de Escrita Criativa pode parecer "ofuscantemente óbvia", e todos acham que sabem do que se trata, então ninguém se detém a pensar sobre isso. É o que afirma a professora da Universidade de Cumbria (Inglaterra), Karen Lockney, na introdução do artigo intitulado "Creativity Across The Curriculum: Creative Writing Beyond English" (2012, p. 43). Lockney defende a presença da Escrita Criativa não só na universidade, mas também no Ensino Fundamental e Médio, e não apenas nas aulas de língua e literatura, mas também nas de outras disciplinas. A Escrita Criativa, assevera a professora, apresenta muitas possibilidades, tanto em ficção quanto em não ficção. No entanto, antes de usufruir

\footnotetext{
${ }^{3}$ Outras noções da literatura como encontro podem ser observadas em Mikhail Bakhtin, que considera "a natureza sociológica da estrutura da expressão e da atividade mental" (1979, p. 130), o que confere à linguagem e, por consequência, à literatura um caráter dialógico. $\mathrm{E} o$ dialogismo se manifesta, primeiramente, na conjunção de vozes dentro do texto e se estende à leitura, na construção de sentido do texto; Wolfgang Iser, com sua proposta de que "os autores jogam com os leitores e o texto é o campo do jogo" (ISER, 2002, p. 107). Por esse viés, autor e leitor se encontram na estrutura do texto, que é o esboço de um mundo proposto pelo autor para ser concretizado e interpretado pelo leitor; Roland Barthes, que constrói o raciocínio de que "não há texto sem filiação [...], de geração espontânea" (2005, p. 23). A literatura seria, antes de tudo, um encontro entre o escritor e outros escritores amados por ele, um encontro com "uma espécie de objeto global: a Literatura (BARTHES, 2005, p. 22)". Registro tais noções, evidenciando que o artigo não teria como dar conta da complexidade de cada uma delas; ainda que também possam ser pensadas em termos de oficina literária, não é a proposta aqui.

${ }^{4}$ Um histórico da trajetória da Escrita Criativa no meio universitário ao redor do mundo e no Brasil pode ser encontrado no meu artigo "O fantasma, o elefante e o sótão: apontamentos sobre a escrita criativa na academia”, na revista Cenários, v. 1, n. 9 (2014).
} 

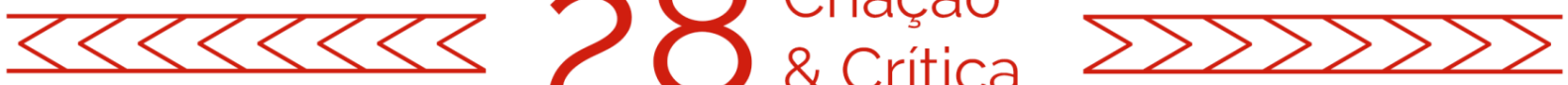

delas, de acordo com Lockney, vale a pena parar por um momento para pensar no que exatamente se quer dizer quando se usa a expressão Escrita Criativa.

Dois livros inevitáveis para os interessados no tema são The Elephants Teach Creative Writing since 1880 (1996), de D. G. Myers, e Creative Writing and the New Humanities (2005), de Paul Dawson. Myers realiza uma extensa e até então inédita pesquisa histórica para investigar as origens e o desenvolvimento dos programas de Escrita Criativa nas universidades dos Estados Unidos. Problematiza o fato de esses programas formarem mais professores de escrita do que escritores. Dawson aponta que a Escrita Criativa surgiu vinculada à Teoria da Literatura, para depois se afastar dela, o que faz com que seja o sótão da "torre de marfim" (2005, p. 15) da universidade. Na visão dele, o caminho para escapar dessa condição é se abrir à teoria (as New Humanities) e encampar demandas da sociedade. Ambos explicitam suas visões de Escrita Criativa, que, naturalmente, estão em consenso com as propostas dos livros.

De acordo com Meyers, a Escrita Criativa é: "(1) Uma matéria de aula, o ensino de ficção e composição de versos em faculdades e universidades por todo o país; e (2) um sistema nacional em prol do emprego de escritores de ficção e poetas para ensinar esses assuntos" (2006, p. XI) ${ }^{5}$. Dawson, por sua vez, define a Escrita Criativa como "uma disciplina, ou seja, um corpo de conhecimento e um conjunto de práticas pedagógicas que operam por meio da oficina literária e estão inseridas no espaço institucional de uma universidade"6 (2005, p. 21-22).

Observemos que ambos dão como superadas a discussão sobre ser de fato possível ensinar Escrita Criativa, pois antes de tudo se trata de "uma matéria de aula" e de "uma disciplina". Reparemos também que Meyers relaciona a Escrita Criativa somente à ficção e à poesia, enquanto Dawson não deixa isso claro, nem fala em formação de escritores, ainda que cite a oficina literária. Constatemos por fim que ambos concebem a Escrita Criativa como parte integrante do ambiente acadêmico. Vejamos agora como as instituições acadêmicas definem a Escrita Criativa.

O TheBestSchools.org é um site que avalia carreiras universitárias nos Estados Unidos. Consta no site que uma avaliação do tipo é sempre uma ciência inexata, mesmo quando se trata de um curso de uma área acadêmica com critérios mesuráveis de modo objetivo, como engenharia, medicina ou administração. No caso da Escrita Criativa, o processo de avaliação, segundo o site, ameaça "afundar num pântano de subjetividade" 7 . A razão seria porque a Escrita Criativa é "um conceito que varia de instituição para instituição, mas costuma abranger poesia, alta literatura, literatura de massa, escrita de peça de teatro, escrita de roteiros, e, também, não ficção"8.

\footnotetext{
${ }^{5}$ Tradução do autor, do original: (1) A classroom subject, the teaching of fiction and verse-writing at colleges and universities across the country; and (2) No original: a national system for the employment of fiction writers and poets to teach the subject.

${ }^{6}$ Tradução do autor, do original: a discipline, that is, as a body of knowledge and a set of pedagogical practices which operate through the writing workshop and are inscribed within the institutional site of a university.

7 Tradução do autor, do original: "a slough of subjectivity."

8 Tradução do autor, do original: "a concept which varies from school to school, but may comprise poetry,
} 

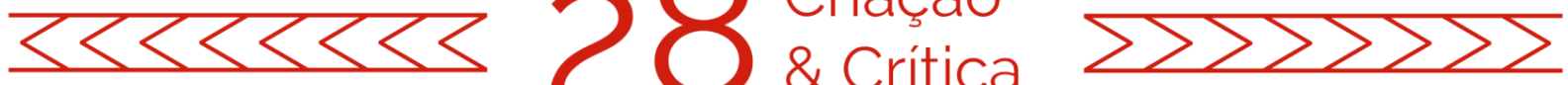

Quando se navega pelos sites das instituições, porém, não se costuma encontrar a explicitação do conceito. Na página do mais tradicional departamento de Escrita Criativa do mundo, o da Universidade de lowa, encontram-se informações sobre o curso de pósgraduação, denominado Creative Writing Program, mais conhecido simplesmente como The lowa Writers' Workshop (A Oficina de Escritores de lowa): "O lowa Writers Workshop é um curso presencial de dois anos, que se finaliza com a entrega de uma dissertação criativa (um romance, uma coletânea de contos ou um livro de poesia) e o recebimento do título de mestre em Belas Artes" 9 . O texto informa sobre o curso - é presencial, dura dois anos, fornece diploma de mestre -, mas não diz propriamente o que é a Escrita Criativa.

$\mathrm{O}$ mesmo acontece nos sites de outras instituições estrangeiras renomadas. $\mathrm{Na}$ página do departamento de Escrita Criativa da Universidade de Columbia ${ }^{10}$, em Nova lorque, descobre-se que os alunos de mestrado precisam de 60 créditos para se formarem, ao contrário dos 48 ou mesmo dos 36 créditos que a maioria dos mestrados nos Estados Unidos exigem. Há áreas de concentração em ficção, poesia, não ficção e ainda em escrita e tradução literárias. Na Universidade Johns Hopkins ${ }^{11}$, em Baltimore, pode-se escolher somente entre as áreas de ficção e poesia. Em Stanford ${ }^{12}$, na Califórnia, a graduação apresenta mais de 100 disciplinas em Escrita Criativa para toda a comunidade acadêmica, com opções de cursos especiais em escrita de romance, ficção jovem-adulta, literatura e cinema, romance gráfico. A página de Escrita Criativa da Universidade de East Anglia ${ }^{13}$, na Inglaterra, chama a atenção para os eventos que o campus recebe durante o ano acadêmico, como o Norwich Crime Writing Festival e o International Literary Festival. Esses são alguns dos melhores lugares para estudar Escrita Criativa, e se percebe uma ideia comum a norteá-los. Nenhum deles, no entanto, conceitua com exatidão a Escrita Criativa. Há uma exceção, que é o caso do Thompson Writing Program, da Universidade de Duke, que define o termo como:

uma forma de expressão artística, que toma como base a imaginação para transmitir significado por meio do uso de figuras de linguagem, narrativa e eventos dramáticos. Isso contrasta com as formas de escrita analíticas ou pragmáticas. O gênero inclui poesia, ficção (romances, contos), roteiros, peças e não ficção ${ }^{14}$.

\footnotetext{
literature, genre fiction, playwriting, screenwriting, and non-fiction."

9 Tradução do autor, do original: "The lowa Writers' Workshop is a two-year residency program which culminates in the submission of a creative thesis (a novel, a collection of stories, or a book of poetry) and the awarding of a Master of Fine Arts degree." Disponivel em: <https://writersworkshop.uiowa.edu/. Acesso em 26 fev. 2020>.

${ }^{10}$ Disponível em: <https://arts.columbia.edu/writing>. Acesso em 26 fev. 2020.

11 Disponível em: <https://writingseminars.jhu.edu/graduate/>. Acesso em 26 fev. 2020.

12 Disponível em: <https://creativewriting.stanford.edu/undergraduate/overview. Acesso em 26 fev. 2020>.

${ }^{13}$ Disponível em: <https://www.uea.ac.uk/literature/creative-writing>. Acesso em 26 fev. 2020.

14 Tradução do autor, do original: Creative writing, a form of artistic expression, draws on the imagination to convey meaning through the use of imagery, narrative and conflict. This is in contrast to analytic or pragmatic forms of writing. This genre includes poetry, fiction (novels, short stories), scripts, screenplays, and creative non-fiction. Disponível em: <https://twp.duke.edu/sites/twp.duke.edu/files/file-attachments/creative-writing1.original.pdf>. Acesso em 3. fev. 2020.
} 

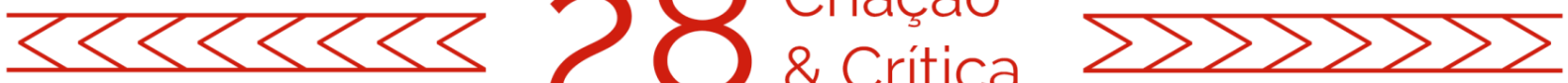

A Escrita Criativa, nesse viés, está associada do modo estrito à expressão artística. Busca transmitir significado, tomando como ponto de partida a imaginação. A ênfase na imaginação, aliás, é um aspecto que permeia a Escrita Criativa, a tal ponto que poeta Allen Tate, quando em 1939 foi contratado pela Universidade de Princeton para lecionar no recém-criado Creative Arts Program, tentou trocar o nome de sua disciplina de Escrita Criativa para Escrita Imaginativa: "Eu perguntei ao reitor Christian Gauss se podíamos mudar [...] e ele disse que achava que não - tinha sido anunciado como "Criativa", e a mudança poderia confundir ${ }^{15 ", ~ r e l e m b r a ~ T a t e ~ n u m ~ a r t i g o ~ d e ~} 1964$ chamado What is Creative Writing e no qual, ao contrário do que o título indica, ele não diz o que é Escrita Criativa. Retomando a definição da Universidade de Duke, constata-se nela a presença da ideia mais comum que se tem da Escrita Criativa, uma forma de escrita que traz embutida a intenção de usar recursos literários e assim produzir arte, seja na forma de narrativa, seja na forma de poema. É uma ideia semelhante à do verbete do Cambridge Dictionary: "atividade de escrever histórias, poemas etc., ou as histórias e poemas que são escritos"16. Contudo, nem todos os intelectuais da área concordam com isso.

Kendall Elizabeth MacVean (2016), em seu trabalho de conclusão de bacharelado em Artes, argumenta que pensar a Escrita Criativa dessa maneira é "maçante e restritivo", já que exclui outras áreas. Ela critica a definição da Universidade de Duke porque:

deixa de fora a beleza da Escrita Criativa e a enquadra como algo incapaz de ser analítico, útil e realista, o que é falso. Essa definição restringe os limites da Escrita Criativa e a descreve como meramente expressiva, não investigativa, questionadora, complicada, sondada ou complexa (MACVEAN, 2016. P. 13) ${ }^{17}$.

A observação se alinha com o trabalho de MacVean. Intitulado Expansion and inclusion of Creative Writing: a course for academic writers, propõe que se pense a Escrita Criativa para além do campo literário. A segunda seção do trabalho, "An Important Definition: What is Creative Writing?" (MACVEAN, 2016, p. 11), inicia-se com a afirmação de que a Escrita Criativa abrange um amplo escopo: cabe em diversos moldes e assume muitas formas diferentes. Por isso, "o próprio termo Escrita Criativa tem um significado maleável e até mesmo subjetivo"18. MacVean faz considerações sobre alguns desses significados, citando pesquisadores que separam o que chamam de "Escrita Criativa acadêmica" e "Escrita Criativa literária"19, o que

\footnotetext{
15 Tradução do autor, do original: I asked Dean Christian Gauss if we migth change [...] and he said he feared not - it had been announced as "Creative", and the change would be confusing.

16 Tradução do autor, do original: the activity of writing stories, poetry, etc., or the stories, poems, etc. that are written. Disponível em: <https://dictionary.cambridge.org/pt/dicionario/ingles/creative-writing>. Acesso em 26 fev. 2020.

17 Tradução do autor, do original: leaves out the beauty of creative writing and frames it as something incapable of being analytical or useful and realistic, which is untrue. This definition narrows creative writing's boundaries and outlines it as merely expressive, not investigative, questioning, complicated, probing, or intricate.

18 Tradução do autor, do original: the term "creative writing" itself is a malleable and even subjective one.

19 MacVean exemplifica com os artigos "More Than Words: Applying The Discipline Of Literary Creative
} 

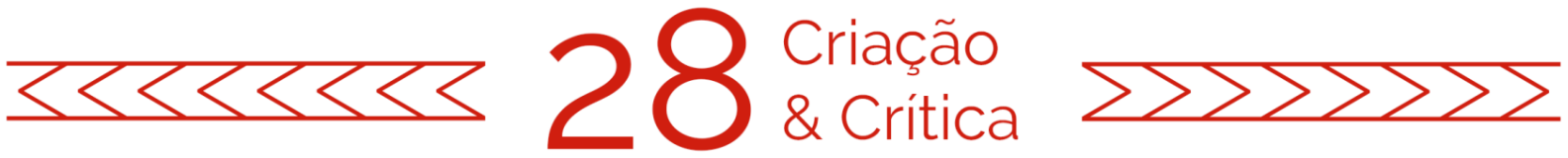

ela acha desnecessário, já que os recursos literários também podem ser usados em textos acadêmicos.

A seguir, ela cita as duas definições de Escrita Criativa que mais lhe agradam (MACVEAN, 2016, p. 13). Uma delas constava no site da Literature Wales, a agência nacional de desenvolvimento da literatura da País de Gales ${ }^{20}$. MacVean menciona apenas a primeira oração: "Escrita Criativa é a brilhante arte de inventar coisas ${ }^{21 " . ~ A ~ d e f i n i c ̧ a ̃ o ~}$ completa é a seguinte:

Escrita Criativa é a brilhante arte de inventar coisas do jeito mais atrativo, adequado e convincente possível. É a contação de mentiras com o objetivo de revelar verdades obscuras e iluminadoras sobre o mundo e nosso lugar nele. Tendemos a pensar em poesia, ficção e peças de teatro ${ }^{22}$.

É uma definição poética, por certo, mas que em síntese também limita o uso da Escrita Criativa à produção de textos ficcionais. $E$ a não ficção? $E$ as memórias, autobiografias, jornalismo literário? E os ensaios, pessoais ou não? A outra definição referida por MacVean como favorita é a de Karen Lockney, que consta no artigo citado no início do presente ensaio. Lockney sugere um conceito abrangente, o que se reflete no tamanho. Apesar de ser longo, vale a pena ser citado na íntegra:

Claramente, há um papel para a imaginação; um escritor pode se basear nos fatos ou na "vida real", mas tem a liberdade de estender isso até os reinos da ficção; a escrita pode se atrelar a formas reconhecíveis - poesia, peça teatral, diário etc. - ou - neste mundo pós-moderno - brincar inteiramente com a forma. A Escrita Criativa pode ser publicada por grandes editoras ou trancada na gaveta para nunca ser lida por ninguém que não seja o autor. Os vencedores do Prêmio Nobel praticam a Escrita Criativa, assim como as crianças em idade pré-escolar. Algumas pessoas praticam a Escrita Criativa porque sonham em ser publicadas por editoras, outras simplesmente escrevem porque gostam; pode ser até apenas no âmbito privado (diários, por exemplo). Algumas pessoas encaram a Escrita Criativa como parte de um processo de cura (daí seu uso em certos contextos terapêuticos) (LOCKNEY, 2012, p. 43) ${ }^{23}$.

\footnotetext{
Writing To The Practice Of Reflective Writing In Health Care Education", de Lisa Kerr; e "Academically informed Creative Writing in LIS Programs and the Freedom to be Creative", de Keren Dali, Andrea Lau, and Kevin Risk.

${ }^{20}$ A definição não se encontra mais no site (www.literaturewales.org), mas é citada em outras páginas de internet.

${ }^{21}$ Tradução do autor, do original: Creative writing is the very fine art of making things up.

22 Tradução do autor, do original: Creative writing is the very fine art of making things up, in the most attractive, apt and convincing way possible. It's the telling of lies in order to reveal illuminating and dark truths about the world and our place in it. We tend to think of Poetry, Fiction, and Plays.

${ }^{23}$ Tradução do autor, do original: Plainly, there is a role for the imagination; a writer may draw on fact or on 'real life' but is at liberty to extend this as far as they wish into the realms of fiction; the writing may fall into recognisable forms--poetry, a play script, a diary entry etc., or-in this postmodern world--play with form entirely. Creative writing gets published by Penguin, Faber and Random House, or it is locked away in the sock drawer never to be read by anyone other than the author. Nobel Prize winners engage in creative
} 

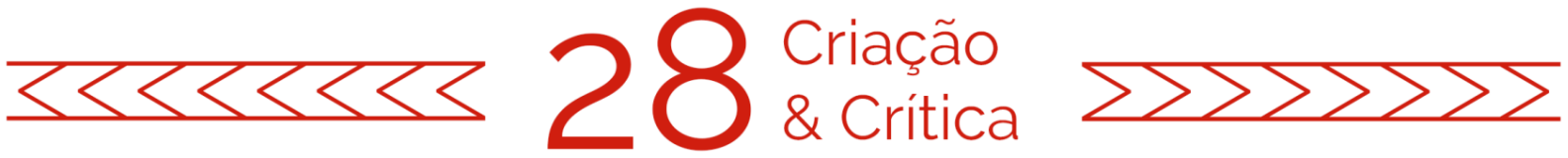

Lockney enxerga Escrita Criativa como um tipo de escrita que usa a imaginação, mas vai além. Tanto escritores premiados quanto crianças que ainda nem sabem escrever praticam a Escrita Criativa, que pode então ser usada para além da literatura. Baseada nesse pressuposto, e claramente inspirada por Lockney, MacVean (2016, p. 14) também propõe uma definição:

Escrita Criativa é o processo de criação por meio da escrita que demanda atenção, concentração e imaginação direcionadas para a produção de um texto original e que possua significado e valor, mesmo que apenas para o escritor. A forma e o conteúdo da Escrita Criativa podem variar num amplo espectro, mas costuma envolver pensamento imaginativo e a criação de algo novo ${ }^{24}$.

Reparemos: sob esse ponto de vista "um texto original e que possua significado e valor" e o fato de a Escrita Criativa "envolver pensamento imaginativo" não têm a ver com a produção ficcional nem com criação literária no sentido de cunhar textos que se encaixem nos gêneros épico, lírico o dramático.

Até aqui foram reunidas e comentadas definições de Escrita Criativa em língua inglesa, sobretudo porque o termo surgiu nos Estados Unidos e, antes de se espalhar pelo mundo, ficou conhecido em outros países anglófonos. Na sequência deste trabalho, apresenta-se uma compilação de definições em língua portuguesa.

"O que é, enfim, a Escrita Criativa (EC)?", pergunta o português João de Mancelos (2009, p. 13) num livro introdutório ao assunto, para em seguida dizer: "Ou, como eu prefiro perguntar, o que não é a EC?".

Mancelos comenta como, apesar do sucesso, a partir dos anos 2000, dos cursos de Escrita Criativa - "normalmente designados por oficinas" - em Portugal, ocorre no país lusófono uma confusão a respeito do que são e de como funcionam esses cursos. A confusão, segundo ele, leva a preconceitos em geral motivados por desconhecimento um raciocínio que pode ser estendido, em minha opinião, ao contexto brasileiro ${ }^{25}$. Com vistas a mudar esse cenário, Mancelos desconstrói o folclore em torno das oficinas:

writing, and so do pre-school children. Some people engage in creative writing because they dream of being courted by one of the aforementioned publishing houses, others simply write because they enjoy it; it may even be intensely private (diaries, for instance). Some people view it as part of a healing process (hence its use in some therapeutic contexts).

${ }^{24}$ Tradução do autor, do original: Creative writing is the process of creation through writing that involves a focused and imaginative attention to originally producing a text that holds meaning and value, if only to the writer. Its form and content can range all across the spectrum, but most involve imaginative thought and the creation of something new.

25 Tomemos, por exemplo, o texto assinado por Mateus Baldi na revista Piauí de julho de 2019. Intitulado "Nunca fomos tão cool" e subtitulado "Como os cursos de escrita criativa (e a internet) estão transformando potenciais escritores em emuladores profissionais", o texto ridiculariza o curso .TXT, organizado por Reginaldo Pujol, Cristiano Baldi (com quem o autor frisa não ter nenhum parentesco) e Rodrigo Rosp. $O$ curso talvez não tenha sido bem sucedido, o que não justifica o tom de escárnio do texto em relação à Escrita Criativa como um todo - e o que é pior, sem embasar as afirmações. 

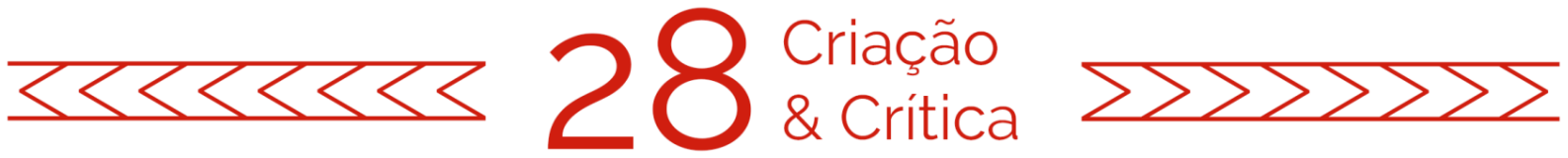

a) Uma oficina bem concebida não visa transmitir receitas, mas sim técnicas;

b) Não institui regras, mas antes incentiva à experimentação e ao desejo de inovar, mesmo que tal implique voltar as costas aos autores que influenciaram o aprendiz;

c) Não promete êxito comercial, mas procura a qualidade, através da técnica, do trabalho árduo, da disciplina, da leitura de grandes obras do passado e do presente;

d) Não se restringe apenas a exercícios, como acontece quase sempre em Portugal, mas antes procura um equilíbrio entre a ampla teoria da escrita criativa e a prática (Mancelos, 2009, p. 13)

Por fim, ao "estabelecer opostos" e assim desfazer enganos, Mancelos delineia um conceito que, salienta, não é "meramente pessoal", baseia-se na leitura de dezenas de obras especializadas em língua inglesa e francesa. Afirma que a Escrita Criativa consiste:

no estudo crítico, na transmissão e no exercício de técnicas utilizadas por escritores e ensaístas de diversas épocas e culturas, para a elaboração de textos literários (contos, novelas, romances, poemas, guiões, entre outros) ou não literários (artigos de jornal, reportagens, ensaios, etc.) (MANCELOS, 2009, p. 14).

A qualidade da definição acima se dá por sua abrangência em relação à dinâmica de oficina, que consiste na transmissão de técnicas, tomando como base a leitura atenta de textos exemplares e exercícios elaborados para pôr em prática o que a leitura atenta revelou. Não restringe a Escrita Criativa ao ambiente acadêmico, englobando a ficção e a não ficção, a literatura e o que Mancelos chama de "não literatura".

Se a Escrita Criativa faz sucesso em Portugal desde a virada o século, faz mais sucesso e há mais tempo no Brasil. Aqui já granjeou espaço na universidade desde 1985, ano da implantação da Oficina de Criação Literária da PUCRS, desde o início ministrada por Luiz Antonio de Assis Brasil| ${ }^{26}$. A página da oficina informa como o curso funciona. Os participantes têm contato com a experimentação narrativa,

[...] à busca da competência nos recursos que a ficção oferece; outrossim, realizam-se certos jogos, na intenção de mostrar ao aluno de que ele é capaz de criar. Ademais, estudam-se o tempo da narrativa, o espaço, o diálogo, as estruturas narrativas etc., e isso acontece não apenas na intenção de sabê-los - coisa que um curso de letras dá conta -, mas para evidenciar o arsenal técnico que um escritor deve possuir. Na Oficina não se ensinam modelos, mas, sim, instrumentos. ${ }^{27}$

Podemos enxergar aí um conceito implícito de Escrita Criativa: uma espécie de laboratório textual. O que ocorre num laboratório? Ora, experimentos, ensaios,

\footnotetext{
${ }^{26}$ A trajetória da oficina pode ser encontrada em Como tudo começou: a história e 35 histórias dos 35 anos da Oficina de Criação Literária da PUCRS (EdiPUCRS, 2020).

${ }^{27}$ Disponível em: <http://www.pucrs.br/humanidades/oficina-de-criacao-literaria/\#apresentacao>. Acesso em 26 fev. 2020.
} 

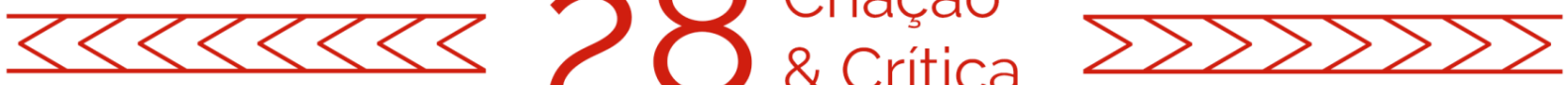

verificações. Nesse caso, tudo isso se direciona à criação literária. Aprende-se experimentando as técnicas.

Além de ter revelado escritores que figuram nas listas dos maiores prêmios literários do país, a Oficina de Criação Literária da PUCRS, um curso de extensão, deu origem a uma linha de pesquisa (2006) e a uma área de concentração (2012) na pósgraduação em Letras, e a um curso de graduação (2016). Também impulsionou o interesse de outras instituições de Ensino Superior pela Escrita Criativa. A expansão do eixo de estudos no meio universitário brasileiro não quer dizer, porém, que se faça pesquisa sobre o tema. Marcelo Spalding Perez e Luiz Antonio de Assis Brasil investigaram o assunto no artigo "A escrita criativa nos cursos de pós-graduação strictu sensu das universidades brasileiras" (2018). Analisaram 28 programas de pós-graduação com nota acima de 5 na Avaliação Quadrienal 2017 da Capes. Apenas um dos programas (o da PUCRS) estabeleceu uma área de concentração em Escrita Criativa e somente mais um possui uma linha de pesquisa com o termo no título (UFRGS). O curioso, afirmam os autores (2018, p. 217), "é que nem o termo 'produção textual' aparece nos títulos das áreas de concentração ou linhas de pesquisa", o que, sugerem Spalding Perez e Assis Brasil, indicia uma dificuldade de lidar não somente com a Escrita Criativa, mas também uma dificuldade "de se trabalhar com a escrita como um todo" no âmbito acadêmico.

Talvez parte da dificuldade seja fruto de não se saber com exatidão do que se trata a Escrita Criativa, o que, como apontou João de Mancelos, origina ideias errôneas e preconceituosas acerca do assunto. Não é o caso, sem dúvida, da PUCRS e da UFRGS. No Programa de Pós-Graduação em Letras da UFRGS uma das linhas de pesquisa dentro da área de concentração em Estudos da Literatura se denomina Estudos literários aplicados: Literatura, Ensino e Escrita Criativa. A explicação:

Ensino e difusão da literatura no plano da escola e da sociedade, considerando a formação do leitor. Representações da leitura. Literatura contemporânea em suas diversas manifestações. Proposta de novas práticas discursivas no âmbito da oralidade e da escrita. Processo de criação em diferentes dimensões, tanto no sentido da produção de uma obra ficcional própria quanto no sentido do estudo do processo de criação de outro autor. Tal estudo pode se dar a partir de documentos de processo (crítica genética), a partir da obra publicada, a partir de correspondências e de entrevistas ${ }^{28}$.

Nesse caso, pode-se considerar a Escrita Criativa como a pesquisa sobre o processo de criação. A pesquisa pode se desenvolver "tanto no sentido da produção de uma obra ficcional própria quanto no sentido do estudo do processo de criação de outro autor". Reparemos que a Escrita Criativa está ligada à ficção e à crítica genética. 0 texto guarda algumas similaridades com o que consta no site da pós-graduação da PUCRS, que, talvez por já ser uma área de concentração, oferece uma apresentação mais completa:

${ }^{28}$ Disponível em: <https://www.ufrgs.br/ppgletras/linhas/>. Acesso em 26 fev. 2020. 

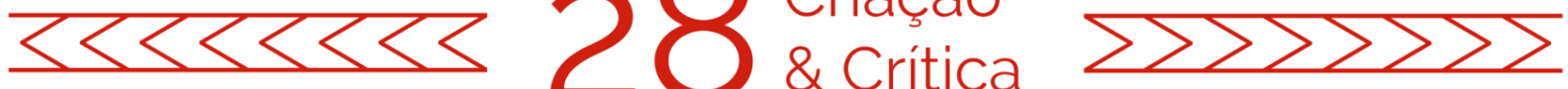

A área de concentração em ESCRITA CRIATIVA, com ênfase interdisciplinar, tem uma linha de pesquisa específica: Leitura, Criação e Sistema Literário. Investiga a gênese de textos literários e não literários, sua relação com outras linguagens, a inclusão do escritor no sistema literário, apoiada em teorias críticas da literatura e em documentos de escritores sobre o processo de criação. Seu foco volta-se à criação literária e seus fundamentos estéticos, à crítica genética, às relações entre literaturas e outras mídias, produção de roteiros teatrais e fílmicos e criação de textos não literários ${ }^{29}$.

Assim como o texto da UFRGS, a maior parte deste aborda os aspectos teóricos, incluindo a crítica genética. Em contrapartida, a apresentação da PUCRS deixa claro que a Escrita Criativa é uma área cujo "foco volta-se à criação literária e seus fundamentos estéticos [...], produção de roteiros teatrais e fílmicos e criação de textos não literários". Há uma ampliação do horizonte da Escrita Criativa na academia, já que também se incluem peças e roteiros, além de textos não literários. E como não se usa a palavra ficção, supõe-se que a não ficção esteja contemplada no campo da criação literária.

É preciso salientar que as definições elencadas até aqui, em sua maioria, dizem respeito à Escrita Criativa como disciplina acadêmica, o que de fato condiz com sua natureza em parte, mas não apenas. Uma reportagem de 2017 da revista Exame tem o chamativo título de "O que é escrita criativa e como ela pode salvar qualquer carreira". Para redigi-la, a jornalista Claudia Gasparini ouviu, entre outros, o escritor Reginaldo Pujol Filho. Egresso da pós-graduação da PUCRS, Pujol forneceu a seguinte definição, ou ao menos suas palavras foram assim filtradas pela reportagem: "campo de estudo acadêmico que nos permite investigar, refletir e teorizar sobre o texto literário, a partir da prática ${ }^{30 "}$. É verdade que a Escrita Criativa se desenvolveu no meio universitário e continua sendo fortemente praticada nele. Tanto na pós-graduação, assim como nos cursos de graduação em Escrita Criativa, a espinha dorsal - e desde o início (DAWSON, 2005; MYERS, 1996; MCGURL, 2009) - são as oficinas literárias. Contudo, as oficinas ocorrem também, e, quiçá, principalmente, fora da universidade. Tomemos o exemplo do francês Alain André. Em 1985, André fundou o Aleph Écriture, um centro de formação de escritores sem ligação institucional com a universidade, que no entanto é referência quando se fala de Escrita Criativa na Europa - André é membro fundador e já foi vice-presidente da European Association of Creative Writing Programmes (EACWP). Também é autor de Devenir Écrivain ${ }^{31}$, um livro-chave para quem se interessa por Escrita Criativa na França, publicado pela primeira vez em 2007, tendo sido reeditado em 2012 e 2018. Há outros inúmeros exemplos, e o próprio Pujol ministra oficinas fora da academia. Portanto, não parece ser o melhor caminho limitar a Escrita Criativa a "um campo de estudo acadêmico".

${ }^{29}$ Disponível em: <http://www.pucrs.br/humanidades/programa-de-pos-graduacao-em-letras/>. Acesso em 26 fev. 2020.

30 Disponível em: <https://exame.abril.com.br/carreira/o-que-e-escrita-criativa-e-como-ela-pode-salvarqualquer-carreira/>. Acesso em 26 fev. 2020.

31 Uma resenha do livro escrita pelo autor deste ensaio foi publicado na revista Scripta Uniandrade, v. 17, n. 3 (2019). 

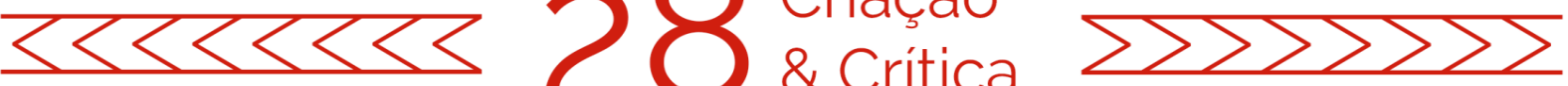

\section{Do que estou falando quando falo de Escrita Criativa}

Esta parte do presente ensaio é composta por reflexões mescladas ao testemunho de minha experiência pessoal como ministrante de oficinas e cursos de criação, no intento de propor uma definição própria de Escrita Criativa. 2018 foi o meu período inicial como professor universitário da área. No primeiro semestre, o extinto grupo de pesquisa Escrita Criativa na academia, do qual fazia parte, publicou o artigo "Apontamentos metodológicos e curriculares discentes para os cursos de pós-graduação em Escrita Criativa no Brasil". Realizamos entrevistas com os alunos para verificar suas impressões acerca das disciplinas oferecidas e os procedimentos metodológicos adotados na área de concentração em Escrita Criativa do Programa de Pós-graduação em Letras da PUCRS. Um dos objetivos era apontar caminhos para o fortalecimento da área no Brasil. Por isso, pesquisamos também como funcionavam os programas de universidades estrangeiras. Nesse aspecto, chamou-me a atenção a explanação da Universidade de Denver para o doutorado em Escrita Criativa:

Nós oferecemos um ambiente para escritores que são leitores sérios e interdisciplinares. Acreditamos que escritores são enriquecidos por uma dieta pesada de grande literatura em conjunção com filosofia, história, teoria crítica e estética, antropologia, história da arte e a história da ciência. Ensinamos os estudantes a ler constantemente, pensar muito, mas apenas raramente colocar essa escrita e pensamento conscientemente na sua escrita. Em vez disso, acreditamos que é a mente por trás do trabalho que é alterada e vai, por sua vez, eventualmente alterar a escrita (Apud BRASIL et al, 2018)

Após a leitura desse trecho, surgiu a reflexão sobre a concepção da Escrita Criativa como um ambiente. No caso da Universidade de Denver, é um ambiente que enriquece os escritores com leituras interdisciplinares. Lembrei-me da oficina que conduzi, na companhia do psiquiatra Luiz Ziegelmann, com participantes de grupos terapêuticos em saúde mental do Hospital Conceição, em Porto Alegre (RS). A oficina, idealizada por Ziegelmann, ocorreu em 2013 e foi uma das primeiras que ministrei - a primeira de longa duração, ao menos. Foram oito meses, com encontros semanais aos quais eu comparecia num misto de empolgação e dúvida. Apesar de ter sentido desde o início uma conexão com aquelas pessoas ${ }^{32}$, me perguntava se estava fazendo um bom trabalho.

Dessa experiência, resultou o livro Contos sem tarja preta (2014), com textos dos participantes. Relendo a apresentação que Ziegelmann (2014, p. 9-10) escreveu para o livro, o seguinte trecho me saltou aos olhos:

O afeto circulou no grupo e tornou o ambiente mais leve, possibilitando autoconfiança, trocas, cumplicidades, gestos solidários e a coragem para se arriscar no processo criativo. Aquela insegurança inicial diante do

\footnotetext{
32 Tinha a impressão de que era apenas circunstancial o fato de estar ali como ministrante e elas como pacientes-participantes. Tivera mais sorte na vida, isso era tudo.
} 

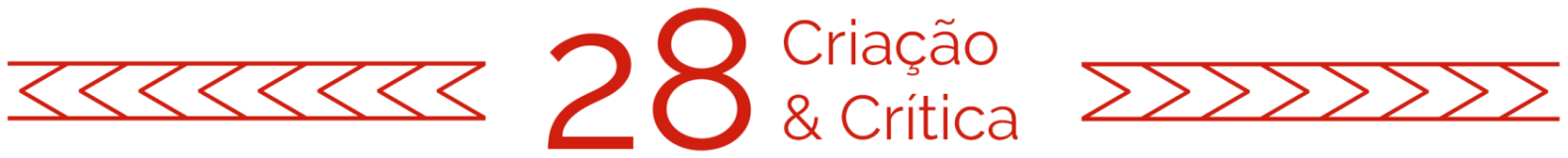

desconhecido, aquele receio que paralisa e inibe a criatividade foi se diluindo. A convicção inicial do "eu não vou conseguir", foi dando espaço para o "eu posso!". A coragem e a determinação foi ganhando vitalidade e possibilitando a aventura, o risco, o desafio de produzir uma escrita informal, debochada, poética e solta.

Embora o contexto não pudesse ser mais diferente daquele da Universidade de Denver, o psiquiatra aponta como o ambiente enriqueceu um grupo que se dispunha a escrever.

No segundo semestre de 2018, ministrei a disciplina Oficina literária IV, para alunos do último semestre do curso de graduação em Escrita Criativa. Agora, após as habituais frustrações e retomadas da prática docente, tinha certa experiência e alguma confiança de que estava cumprindo o meu papel. Um ano depois, um dos alunos, Jairo Loewenstein, pediu-me para orientá-lo no TCC. O assunto era um dos temas que eu trouxe para a oficina, A Escrita Criativa como transgressão: o conto como tranche de vie ${ }^{33}$. No início do trabalho, Jairo relembra a oficina:

Choveu em todas as sextas-feiras do segundo semestre de 2018. Pelo menos é essa a impressão que guardo, e ela se deve às lembranças da disciplina de Oficina Literária que eu frequentava no curso de Escrita Criativa. Meu programa de sexta-feira era chegar na sala de aula meio molhado, guarda-chuva pingando e com vontade de ler meus textos. A turma era pequena - seis alunos - e bem entrosada: líamos nossa produção, comentávamos, sugeríamos, brincávamos com literatura. Funcionava como uma terapia para mim, por isso foi tão marcante a ponto de eu me lembrar de detalhes como a chuva. Mas atenção: a terapia era pedagógica $^{34}$.

Ao fazer o programa da oficina, levei em conta fatores que depois seriam ressaltados por Jairo: o número de alunos e a ementa: "Literatura em sua manifestação textual. Temas avançados em criação literária". Pensei num percurso didático que promovesse a expansão do conceito de narrativa. Com o estranhamento de alguns alunos, a adaptação veio por meio do tempo e de algumas alterações no programa inicial. A aula acontecia às sextas-feiras, das $19 \mathrm{~h} 30$ às $21 \mathrm{~h}$, e várias vezes ficávamos até $21 \mathrm{~h} 15$, $21 \mathrm{~h} 20$, até $21 \mathrm{~h} 30$. Por quê? O relato de Jairo também indica uma resposta: além de pequena, a turma era "bem entrosada: líamos nossa produção, comentávamos,

\footnotetext{
${ }^{33}$ A tranche de vie também virou um curso que ministrei no âmbito da pós-graduação do Instituto Vera Cruz, em São Paulo. Disponível em: <https://site.veracruz.edu.br/instituto/eventos/escrita-criativa-e-transgressaoo-conto-como-tranche-de-vie/>. Acesso em 09 mar. 2020. Sobre o tema, Jairo Loewenstein escreveu um ensaio sobre o tema em seu TCC.

${ }^{34}$ A continuação do relato: "A proposta envolvia a leitura e discussão de autores consagrados e, a partir disso, a produção textual. O programa contava com uma série de elucubrações: Elucubrações kafkianas; Elucubrações gonçalianas; Elucubrações sobre o excesso; Elucubrações sobre a concisão. Isto é, os temas e critérios técnicos identificados nessas obras serviam de subsídio para o que produzíamos: lemos $A$ metamorfose e tentamos reproduzir os sonhos intranquilos de Gregor Samsa; Lydia Davis nos ensinou concisão, Saramago o excesso. Tudo isso estava no programa da disciplina, que condizia com a ementa: Temas avançados em criação literária".
} 

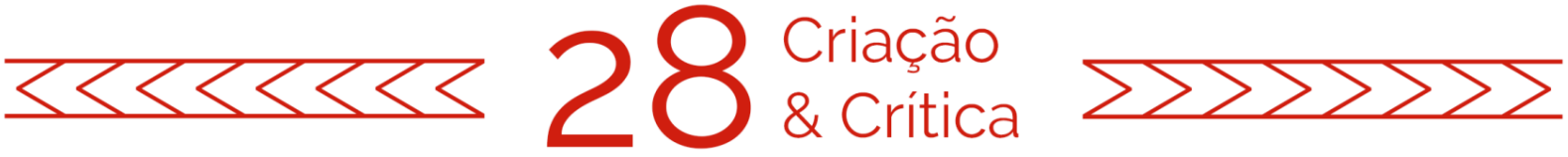

sugeríamos, brincávamos com literatura. Funcionava como uma terapia para mim" ${ }^{35}$. Mesmo sendo uma disciplina de um curso universitário, com ementa, objetivos e programa de ensino a serem seguidos - todos os requisitos foram cumpridos com sucesso -, o tempo em sala de aula foi percebido como uma "terapia pedagógica". Dizendo com outras palavras: funcionou. E por quê? Conforme os testemunhos dos alunos, conseguimos construir "um ambiente para escritores que são leitores sérios e interdisciplinares", em que "o afeto circulou no grupo e tornou o ambiente mais leve, possibilitando autoconfiança, trocas, cumplicidades, gestos solidários e a coragem para se arriscar no processo criativo".

Em 2009, a pedido da Folha de S. Paulo, Daniel Galera descreveu sua participação como aluno em 1999 num "curso de técnicas de leitura e escrita que, de forma 'surpreendente e inevitável', fez dele um autor". Galera se refere à Oficina de Criação Literária da PUCRS ${ }^{36}$. Uma vez envolvido na dinâmica dos encontros semanais da oficina, Galera relata que nunca produziu tanto como ao longo daquele ano. A oficina e, pode-se supor, o ambiente que ele vivenciava ali, estimulavam o escritor aprendiz, que produzia porque sabia que "os textos seriam analisados pelo professor e exaustivamente debatidos pelos alunos, que acumulavam cada vez mais ferramentas para a tarefa". O resultado foi que no final de 1999 Galera decidiu que escrever seria prioridade em sua vida.

De minha parte, decidi que escrever seria prioridade em minha vida no mesmo ano em que li o texto de Galera. Não me lembro se o texto me influenciou de modo direto, mas, no segundo semestre de 2009, pedi demissão do jornal O Estado de $S$. Paulo porque queria me dedicar à escrita. Precisava de tempo para isso, mas não somente. Precisava de estímulo, de pessoas que levassem o ofício a sério. Logo após pedir demissão, ainda em São Paulo, cursei o Núcleo Sesi-British Council de Dramaturgia, às quartas-feiras à noite, no Centro Cultural Fiesp, comandado por Marici Salomão, e a oficina ministrada por Marcelino Freire, às quintas-feiras à noite, no Centro Cultural Barco. Embora essas oficinas tenham me agregado saberes, a verdade é que não me adaptei a elas. Eu não gostava das metodologias - ou do que percebia como a falta delas. Eu não criei laços fortes com os colegas. Então, no início de 2010, fui aceito na Oficina de Criação Literária da PUCRS, decidi me mudar para Porto Alegre, e as coisas começaram a acontecer. Naquele momento, a oficina (e depois o mestrado) foi o que eu precisava, pois me proporcionou contato frequente e meticuloso com a criação literária. Na PUCRS, encontrei acolhimento na figura do Luiz Antonio de Assis Brasil, na atenção que ele nos dispensava, nas aulas em que se percebia um percurso didático claro, planejado de antemão. Eu me enturmei com os colegas, muitos de fora do Estado e que estavam em Porto Alegre por causa da oficina. $E$ fomos bem recebidos pelos que já moravam aqui. A monitora da oficina cuidava para que nos entrosássemos. Os participantes formaram um grupo. Nós nos

\footnotetext{
${ }^{35}$ Os trechos do TCC foram citados com a autorização do aluno.

${ }^{36}$ A expressão "surpreendente e inevitável" costuma ser proferida por Assis Brasil em aula para se referir aos finais de contos ou romances, e consta num manual de escrita em que colaborei com ele: Escrever ficção (2019).
} 

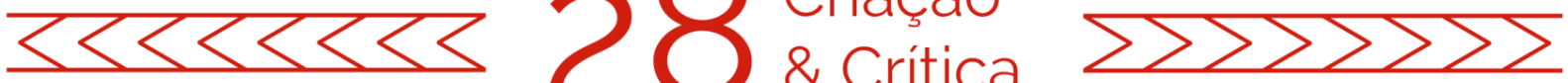

líamos, nas aulas e fora dali. Nós nos reuníamos. Eu me lembro de que fiz uma festa junina em casa no dia do jogo do Brasil na Copa do Mundo. Pelo menos naquele ano, criamos laços e levamos a sério a literatura.

Pesquisando para o presente texto, encontrei relatos semelhantes. Em "My writing education: a time line", publicado na revista The New Yorker, o vencedor do Pulitzer, George Saunders, conta como a experiência de participar do Syracuse Creative Writing Program mudou sua vida. Ele tinha então 27 anos quando recebeu uma ligação do renomado escritor e professor Tobias Wolff informando-Ihe que ele fora aceito. Dirigiu então seu carro do Texas, onde vivia, para o Estado de Nova lorque, onde ficava a universidade. A convivência com Wolff e outros professores, que organizavam jantares e atividades culturais, além do fato de que estava inserido num grupo de aspirantes a escritores, proporcionou a Saunders a certeza de que poderia ter um futuro na área. Ele ainda conheceu ali Paula Redik, uma colega de curso com quem se casou, teve filhos e com quem continua casado até hoje.

Mark Mcgurl, autor de The Program Era: Postwar Fiction and the Rise of Creative Writing, um livro que mostra como a Escrita Criativa moldou a história da literatura estadunidense a partir da década de $1950^{37}$, disse numa entrevista que um curso de Escrita Criativa pode ser um abrigo de um mundo que fica repetindo que se deve "ganhar a vida de forma mais rentável" 38 . Helen Benedict, hoje professora na Universidade de Columbia, escreveu sobre o fenômeno da Escrita Criativa para a edição de 23/05/1982 do The New York Times. O texto se chama "The famous writing schools" e aborda a razão da Escrita Criativa ser um curso tão procurado. A resposta: "Primeiramente, ao que parece, por causa do contato humano ${ }^{39 " . ~ A ~ E s c r i t a ~ C r i a t i v a, ~ a f i r m a ~ B e n e d i c t, ~ p r o p o r c i o n a ~ a o s ~}$ aspirantes a escritor um senso de comunidade, uma comunidade de leitores e companheiros de luta com as palavras. Acrescentaria que a Escrita Criativa, em sua melhor versão, proporciona um ambiente estimulante. Esse ambiente, no fim das contas, mostra - faz com que se acredite - que "o desejo de produzir literatura não é uma ilusão, mas sim uma vocação respeitável" ${ }^{40}$.

No começo do The Cambridge Introduction to Creative Writing, David Morley assevera que metade do que um escritor precisa aprender tem a ver com fatores psicológicos, a outra metade são as técnicas. Pensando nisso, Morley concebeu o livro como uma série de espaços abertos para discussão, reflexão e prática. Tal concepção, segundo meu ponto de vista, deveria ser a de qualquer oficina, curso ou programa de Escrita Criativa: um espaço, uma atmosfera, um ambiente que incentive o escritor ou o aspirante a escritor tanto na parte psicológica quanto na cognitiva.

\footnotetext{
${ }^{37}$ Não seria absurdo pensar o mesmo do caso brasileiro, se for levado em conta que, conforme mostra a reportagem "Lista dos vinte melhores escritores brasileiros da "Granta" reaviva debate" (Folha de S. Paulo, 16/07/2012), 14 dos 20 "melhores jovens escritores" nacionais escolhidos pela Granta (2012) fizeram oficinas literárias ou estudam literatura na universidade.

${ }^{38}$ Disponível em: <https://www1.folha.uol.com.br/fsp/mais/fs1608200907.htm>. Acesso em 26 fev. 2020.

39 Tradução do autor, do original: Primarily, it seems, for human contact.

40 Tradução do autor, do original: the feeling that their desire to write is not a delusion but a respectable vocation.
} 

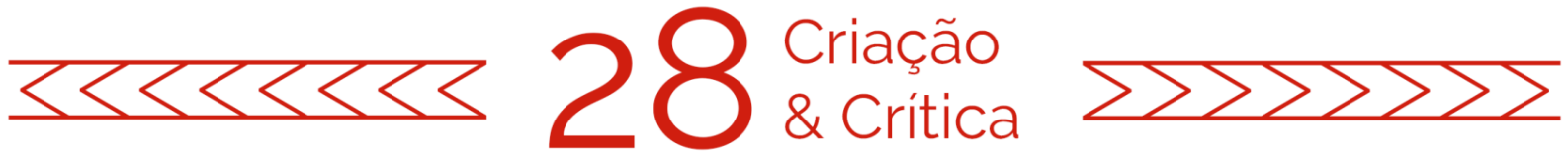

É disso que estou falando quando falo de Escrita Criativa: de um ambiente que estimule a leitura, a pesquisa e, sobretudo, a produção de textos com recursos literários ${ }^{41}$, tanto no campo da ficção quanto no da não ficção. Se isso não ocorre, a oficina, o curso livre, o curso de graduação ou o programa de pós-graduação não funcionam. Vou além: se isso não ocorre, a Escrita Criativa não ocorre.

\section{A título de conclusão}

Voltemos à ideia do ponto de encontro. Encontramos uma visão semelhante à de Luis Sepúlveda na obra Literatura: leitores e leituras, de Marisa Lajolo, quando a autora revela sua concepção da literatura como um "ponto de encontro entre um eu (o leitor) e a escrita de um outro (o escritor)" (LAJOLO, 2001, p. 36). Antes disso, ela reflete sobre a dificuldade de chegar a uma única concepção de literatura. Ousa fazer a pergunta: $O$ que é Literatura? E alinhava uma resposta aberta:

É uma pergunta complicada justamente porque tem várias respostas. E não se trata de respostas que vão se aproximando cada vez mais de uma grande verdade da verdade-verdadeira. Cada tempo e, dentro de cada tempo, cada grupo social tem sua resposta, sua definição (LAJOLO, 2001, p.25).

Neste ensaio transportei o raciocínio da Lajolo: não se pode falar de uma só "verdade-verdadeira" quando tentamos definir a Escrita Criativa. A partir das definições de Escrita Criativa e do relato de minha experiência como ministrante de oficinas, construí uma concepção tendo em mente a ideia do encontro.

Como dito na primeira seção deste ensaio, os encontros conhecidos como oficinas literárias formam a espinha dorsal da Escrita Criativa, um campo que vem ganhando proeminência no Brasil como área acadêmica. Quando falo da Escrita Criativa como um ambiente que estimule a leitura, a pesquisa e, sobretudo, a produção de textos com recursos literários a ideia do encontro está implícita, pois o ambiente agrega e acolhe escritores e aprendizes, professores e pesquisadores. Nesta concepção, o encontro é o que move a Escrita Criativa.

\section{Referências bibliográficas}

AMABILE, L. R. / LINARDI, F./ RICHINITTI, G. (Org.). Como tudo começou: a história e 35 histórias dos 35 anos da Oficina de Criação Literária da PUCRS. Porto Alegre: EDIPUCRS, 2020.

\footnotetext{
41 A expressão "textos com recursos literários" poderia desencadear outro ensaio, pois também existem vários modos de pensar a expressão. Cito algumas: o modo formalista, por meio do uso de figuras poéticas, da busca do estranhamento pela linguagem; o modo da narratologia, por meio das possibilidades do foco narrativo, da construção ou não de um arco narrativo; o modo pós-moderno, lançando mão da paródia, do pastiche, da intertextualidade etc. Digo apenas que todos os modos, a depender do critério do ministrante e dos alunos, podem ser testados numa oficina.
} 

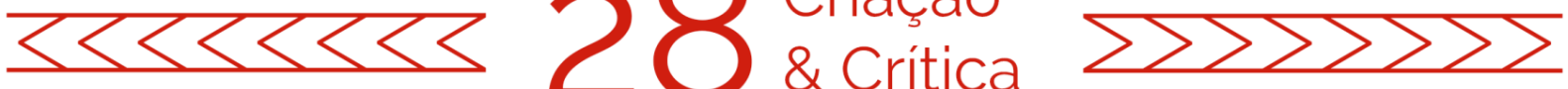

AMABILE, Luís Roberto. "O fantasma, o elefante e o sótão: apontamentos sobre a escrita criativa na academia". Cenários, v. 1, n. 9 (2014), p. 53-61. Disponível em: $<$ https://seer.uniritter.edu.br/index.php?journal=cenarios\&page=article\&op=view\&path\%5B $\% 5 D=862$ \&path\%5B\%5D=545>. Acesso em 20 jul. 2020.

AMABILE, Luís Roberto. "Resenha: Devenir Écrivain - et se faire publier. In: ANDRÉ, Alain. Colaboração de Nathalie Hegron. Paris: Leduc. S, 2018. 480 p. Scripta Uniandrade,

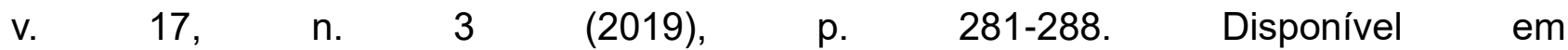
<https://revista.uniandrade.br/index.php/ScriptaUniandrade/article/view/1405/1104>. Acesso em 26 out. 2020.

ANDRÉ, Alain. Devenir Écrivain - et se faire publier. Colaboração de Nathalie Hegron. Paris: Leduc. S, 2018.

BAKHTIN, M. (VOLOCHINOV). Marxismo e filosofia da linguagem - Problemas fundamentais do método sociológico na ciência da linguagem. Tradução de Michel Lahud e Yara Frateschi Vieira com a colaboração de Lúcia Teixeira Wisnik e Carlos Henrique D. Chagas Cruz. São Paulo: Hucitec, 1979.

BARTHES, Roland. A preparação do romance. São Paulo: Martins Fontes, 2005, p. 11.

BENEDICT, Helen. "The famous writing schools". In The New York Times, 23/05/1982.

Disponível em: <https://www.nytimes.com/1982/05/23/books/the-famous-writingschools.html. Acesso em 09/09/2019>. Acesso em 9 set. 2020.

BRASIL, Luiz Antonio de Assis et al. "Apontamentos metodológicos e curriculares discentes para os cursos de pós-graduação em Escrita Criativa no Brasil". Navegações, v. 11, n. 1 (2018), p. 68-75. Disponível em: <https://doi.org/10.15448/19834276.2018.1.33020>. Acesso em 27 out. 2020.

BRASIL, Luiz Antonio de Assis. Escrever ficção - um manual de criação literária. Colaboração de Luís Roberto Amabile. São Paulo: Companhia das Letras, 2019.

CREATIVE WRITING. In: Cambridge Advanced Learner's Dictionary \& Thesaurus. Disponível em: <https://dictionary.cambridge.org/dictionary/english/creative-writing>. Acesso em 09/09/2019.

DALI, Keren/ LAU, Andrea/ RISK, Kevin. "Academically informed Creative Writing in LIS Programs and the Freedom to be Creative". Journal Of Education For Library \& Information Science, v. 56, n. 4 (2015), p. 298-324. Disponível em <https://www.utpjournals.press/doi/abs/10.3138/jelis.56.4.298>. Acesso em 3 nov. 2020.

DAWSON, Paul. Creative Writing and the New Humanities. Londres e Nova lorque: Routledge, 2005.

GARDNER, John. On becoming a novelist. Nova lorque: W.W. Norton, 1999.

ISER, Wolgang. "O jogo do texto". In: LIMA, Luiz Costa (sel., coord. e trad.). A literatura e o leitor: textos de estética da recepção. Rio de Janeiro: Paz e Terra, 2002.

KERR, Lisa. "More than words: applying the discipline of literary creative writing to the practice of reflective writing in health care education". J Med Humanit, vol. 31, n. 4 (2010), p. 295-301. Disponível em: <https://doi.org/10.1007/s10912-010-9120-6>. Acesso em 3 nov. 2020. 

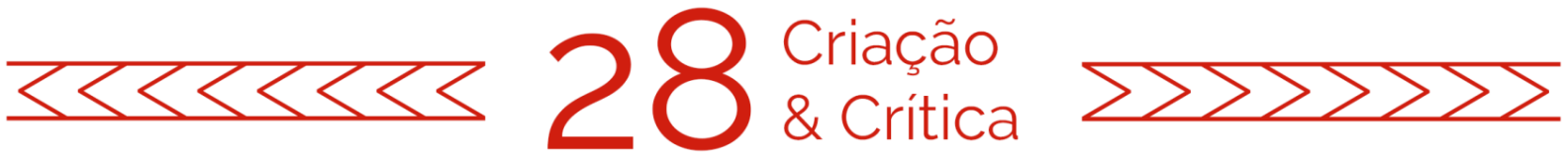

$\mathrm{KOCH}$, Stephen. Oficina de escritores: um manual para a arte da ficção. Trad. de Marcelo Dias Almada. São Paulo: Martins Fontes, 2009.

LAJOLO, M. Literatura: leitores \& leitura. São Paulo: Moderna, 2001.

LOCKNEY, Karen. "Creativity across the Curriculum: Creative Writing beyond English." English Drama Media (2012), p. 43-46.

MACVEAN, Kendall Elizabeth. Expansion And Inclusion Of Creative Writing: A Course For Academic Writers. Trabalho de conclusão de curso (2016). Disponível em <https://libres.uncg.edu/ir/asu/listing.aspx?styp=ti\&id=21425>. Acesso em 20 fev. 2020.

MANCELOS, J. Introdução à escrita criativa, Lisboa: Edições Colibri, 2009.

MCGURL, Mark. The Program Era: Postwar Fiction and the Rise of. Creative Writing. Cambridge: Harvard UP, 2009.

MORLEY, David. The Cambridge Introduction to Creative Writing. Nova lorque: Cambridge University Press. 2007.

SPALDING PEREZ, Marcelo/ BRASIL, Luiz Antonio de Assis. "A escrita criativa nos cursos de pós-graduação stricto sensu das universidades brasileiras". Revista Desenredo, 14 (2) (2018), p. 207-220. Disponível em: <https://doi.org/10.5335/rdes.v14i2.7864>. Acesso em 26 fev. 2020.

TATE, Allen. "What Is Creative Writing?". Wisconsin Studies in Contemporary Literature, vol. 5, n. 3 (1964), p. 181-184.

ZIEGELMANN, Luiz. "Apresentação". In: AMABILE, Luis Roberto; ZIEGELMANN, Luiz (Org.). Contos sem tarja preta. Porto Alegre: Bestiário, 2014.

\section{Programas de cursos/ementas}

Columbia University School of the arts. Disponível em: <https://arts.columbia.edu/writing>. Acesso em 26 fev. 2020.

John Hopkins The Writing Seminars. Disponível em: <https://writingseminars.jhu.edu/graduate/>. Acesso em 26 fev. 2020.

Oficina de Criação Literária da PUCRS - Apresentação. Disponível em: <http://www.pucrs.br/humanidades/oficina-de-criacao-literaria/\#apresentacao>. Acesso em 26 fev. 2020.

PPG Letras UFRGS - Linhas de Pesquisa do Programa. Disponível em <https://www.ufrgs.br/ppgletras/linhas/>. Acesso em 26 fev. 2020.

PUCRS - Escola da Humanidades. Programa de pós-graduação em Letras. Disponível em $<$ http://www.pucrs.br/humanidades/programa-de-pos-graduacao-em-letras/>. Acesso em 26 fev. 2020.

Stanford Creative Writing Program. Disponível em <https://creativewriting.stanford.edu/undergraduate/overview>. Acesso em 26 fev. 2020. University of East Anglia School of Literature, Drama and Creative Writing. Disponível em: <https://www.uea.ac.uk/literature/creative-writing>. Acesso em 26 fev. 2020. 

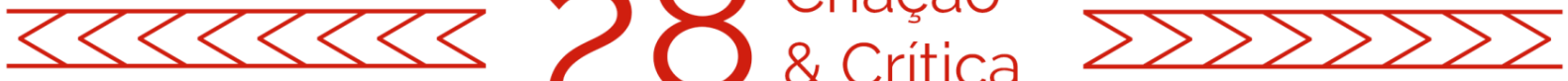

\section{Artigos de jornal}

BALDI, Mateus. "Nunca fomos tão cool". In Piauí, 20/7/2017. Disponível em: <https://piaui.folha.uol.com.br/nunca-fomos-tao-cool/>. Acesso em 6. fev. 2020.

GALERA, Daniel. "Relato de um escritor aprendiz". Folha de S. Paulo, 16/08/2009. Disponível em: <https://www1.folha.uol.com.br/fsp/mais/fs1608200908.htm>. Acesso em 26 fev. 2020.

GASPARINI, Claudia. "O que é escrita criativa e como ela pode salvar qualquer carreira". In Exame, 25/08/2017. Disponível em <https://exame.com/carreira/o-que-e-escritacriativa-e-como-ela-pode-salvar-qualquer-carreira/>. Acesso em 26 fev. 2020.

Sem autor. "Lista dos vinte melhores escritores brasileiros da "Granta" reaviva debate. Disponível em <https://www1.folha.uol.com.br/ilustrada/1120526-lista-dos-vinte-melhoresescritores-brasileiros-da-granta-reaviva-debate.shtml>. Acesso em 3 nov. 2020.

Sem autor. "Luís Sepúlveda, o escritor que via a literatura como ponto de encontro com o leitor". Expresso, 16/04/2020. Disponível em <https://expresso.pt/coronavirus/2020-04-16Luis-Sepulveda-o-escritor-que-via-a-literatura-como-ponto-de-encontro-com-o-leitor>. Acesso em 25 out. 2020.

Recebido em: 24/07/2020

Aceito em: 20/10/2020

Referência eletrônica: AMABILE, Luís Roberto. Do que estamos falando quando falamos de escrita criativa. Criação \& Crítica, n. 28, p., dez. 2020. Disponível em: $<$ http://revistas.usp.br/criacaoecritica>. Acesso em: dd mmm. aaaa. 